\title{
Long-Term Follow-Up of Brain-Damaged Children Requiring Feeding Gastrostomy: Should an Antireflux Procedure Always Be Performed?
}

\author{
By Michael J. Wheatley, John R. Wesley, Daniel M. Tkach, and Arnold G. Coran \\ Ann Arbor, Michigan
}

\begin{abstract}
- Due to the frequent presence of latent gastroesophageal reflux (GER) in mentally impaired children, it is now standard to perform upper gastrointestinal contrast (UGI) and pH probe studies in all children referred for feeding gastrostomy, even if they are without clinical evidence for GER. For patients with documented GER, an antireflux operation performed in conjunction with gastrostomy is usually considered mandatory. Some authors have suggested that a "protective" antireflux operation be performed at the time of gastrostomy placement in all brain-damaged children, citing a high incidence of postoperative GER in this group of patients following gastrostomy, even with a negative preoperative evaluation for GER. To evaluate this theory, we prospectively studied, over the past 6 years, all mentally retarded children referred for feeding gastrostomy with UGI contrast and esophageal $\mathrm{pH}$ probe studies. In total, 148 children were studied; 105 had a positive evaluation for GER and underwent gastrostomy and antireflux surgery. Of the 43 children with a negative preoperative evaluation for GER, 37 are doing well following gastrostomy alone without clinical reflux at an average follow-up of $\mathbf{2 1}$ months. Six of the $\mathbf{4 3}$ $(14 \%)$ developed symptomatic GER occurring at an average of 10 months following gastrostomy placement. Five of these children have been successfully treated with an antireflux operation and the sixth patient has been successfully managed nonoperatively. Given the significant morbidity and mortality that has been documented with antireflux operations in mentally retarded children, we conclude that a protective antireflux operation at the time of gastrostomy placement is not indicated because the data suggest that $86 \%$ of children with a negative preoperative evaluation for GER would undergo the operation needlessly.

Copyright $\odot 1991$ by W.B. Saunders Company
\end{abstract}

INDEX WORDS: Gastroesophageal reflux; fundoplication; mental retardation.

$\mathbf{T}$ ME MAINTENANCE of adequate caloric intake in mentally retarded children can be a very challenging task. Due to the frequent presence of swallowing difficulties, attempts at oral feedings are often unsuccessful, and nasoenteral tube feedings usually prove impractical for institutionalized children. A feeding gastrostomy tube is often recommended to provide nutritional support for these children. Gastroesophageal reflux (GER) is frequently present in brain-damaged children, and as experience with this group of patients has grown, it has become apparent that gastrostomy tube placement can exacerbate preexisting GER.' Reflux in this setting is usually so intractable that it is now standard practice among most pediatric surgeons to perform an antireflux operation in conjunction with gastrostomy for children preoperatively diagnosed with
GER who require feeding tube placement. ${ }^{2}$ However, some authors have suggested recently that a "protective" antireflux operation should be performed in all children, citing a high postoperative incidence of symptomatic GER following gastrostomy placement even in children without demonstrable preoperative GER. ${ }^{3}$ Over the past 8 years, we have prospectively evaluated with preoperative upper gastrointestinal (UGI) radiography and esophageal pH probe monitoring, all mentally retarded children referred to Mott Children's Hospital for feeding tube placement to determine the incidence of symptomatic GER following Stamm gastrostomy in this patient population.

\section{MATERIALS AND METHODS}

From January 1982 to December 1987, 148 neurologically impaired children were referred to the pediatric surgical service for placement of a feeding gastrostomy for nutritional support. This group consisted of 75 boys and 73 girls, with ages ranging from 1 month to 19 years at the time of referral. All children initially undenwent an UGI contrast study and, if GER was not demonstrated, 24-hour esophageal $\mathrm{pH}$ monitoring was then performed. The radiographic examinations were performed using a standard approach to diagnose GER as described by McCauley et $\mathrm{al}^{4}$ and Blane et al. ${ }^{5}$ Reflux was considered to be present radiographically if contrast appeared above the distal esophagus after once clearing completely. Pathological reflux was defined as two or more episodes of reflux to or above the carina after initial clearing of contrast material.

Distal esophageal $\mathrm{pH}$ probe monitoring was performed using a 4-mm Beckman pH probe (Beckman Instruments Inc, Novi, MI) and a portable recorder (Digitrapper Series 6000, Biosearch Medical Products, Somerville, NJ). The probe was passed transnasally and positioned 4 to $5 \mathrm{~cm}$ proximal to the cardioesophageal junction. Position was confirmed using chest radiography. Patients were allowed a regular diet with no snacks. All children were monitored for 24 hours. The $\mathrm{pH}$ monitor recorded four parameters: (1) percentage of time that the $\mathrm{pH}$ was lower than 4 (normal, $<4.2 \%$ ); (2) the number of reflux episodes (defined as a $\mathrm{pH}<4$; normal, $<50$; (3) the number of reflux episodes lasting 5 minutes or more (nomal, 3 or fewer); and (4) the duration of the longest episode of reflux (normal, $<9.2$ minutes). The GER index

From the Section of Pediatric Surgery, Mott Children's Hospital and Henry Ford Hospital, University of Michigan Medical School, Ann Arbor, MI.

Presented at the 21st Annual Meeting of the American Pediutric Surgical Association, Vancouver, British Columbia, May 19-22, 1990. Address reprint requests to John $R$. Wesley, MD, Mott Childrens Hospital, Room F7516, Box 0245, Ann Arbor, MI 48109.

Copyright (1) 1991 by W.B. Saunders Company

0022-3468/91/2603-0011\$03.00/0 
was calculated using the formula $X+4 Y=$ GER index, where $X$ is the number of episodes of a pII $\leq 4$ and $\mathrm{Y}$ is the number of episodes of a $\mathrm{pH} \leq 4$ for more than 5 minutes. A normal index is $\leq 50{ }^{6}$ When three of the five parameters were positive, a diagnosis of significant GER by $\mathrm{pH}$ monitoring was made. All patients with either a positive UGI study or a positive $\mathrm{pH}$ study underwent Stamm gastrostomy placement with the addition of a Nissen fundoplication and posterior gastropexy (Nissen-Hill). Children in whom both radiographic and $\mathrm{pH}$ studies failed to show GER underwent only Stamm gastrostomy placement. Follow-up was performed via postoperative clinic visits and phone contact with family members.

\section{RESULTS}

Of the 148 neurologically impaired children referred to the pediatric surgery service at Mott Hospital for feeding gastrostomy, 105 had a positive evaluation for GER using the above criteria and underwent gastrostomy and Nissen-Hill fundoplication (Fig 1). The surgical morbidity in this group was $18 \%$, with one postoperative death (Table 1). The remaining 43 children underwent Stamm gastrostomy following a negative preoperative evaluation for GER; 37 of these children are doing well without clinical reflux with an average follow-up of 21 months. One child in this group developed a pneumonia following gastrostomy, representing the only postoperative complication. Six of the 43 with a normal preoperative evaluation and gastrostomy placement alone subsequently developed symptomatic GER, confirmed with postoperative UGI and $\mathrm{pH}$ probe monitoring, and five required Nissen-Hill fundoplication. The parents of the remaining child refused fundoplication despite the documented presence of postgastrostomy GER, and she has been successfully managed with continuous feedings through a gastrojejunal feeding tube. The average time from gastrostomy placement to onset of symptomatic reflux was 10 months (range, 4 to 20 months). Reflux in the five surgically treated patients resolved following Nissen-Hill fundoplica-

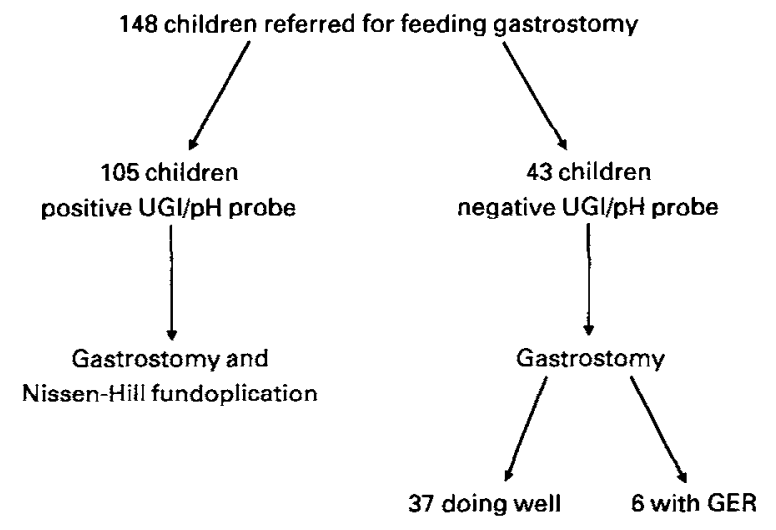

Fig 1. Outcome of 148 children referred for feeding gastrostomy.
Table 1. Surgical Morbidity Following Nissen-Hill Fundoplication

\begin{tabular}{cl}
\hline No. of Patients & \multicolumn{1}{c}{ Complication } \\
\hline 6 & Reflux requiring redo fundoplication \\
4 & Small bowel obstruction \\
2 & Reflux managed medically \\
2 & Stricture requiring dilatation \\
2 & Gastric atony \\
1 & Splenic laceration \\
1 & Pneumonia \\
1 & Disruption of gastrostomy tube \\
1 & Death \\
\hline
\end{tabular}

NOTE. Total: 19 complications (17\%), 1 death (1\%).

tion, although two patients in this group required subsequent reoperation and a second fundoplication for wrap breakdown. There were no operative deaths for the group of 43 children managed initially with gastrostomy placement.

\section{DISCUSSION}

Mentally retarded children frequently have feeding difficulties, culminating in severe malnutrition and referral for gastrostomy placement. ${ }^{7}$ The reported incidence of GER in brain-damaged children ranges from $15 \%$ to $75 \%$, , with a $71 \%$ incidence documented in the present 143 patients. Placement of feeding gastrostomy in such children with reflux can be hazardous, leading to severe vomiting and recurrent aspiration. ${ }^{9}$ Therefore, it is now standard practice in many medical centers to perform an antireflux procedure in conjunction with feeding gastrostomy in patients with documented reflux. ${ }^{2.310}$ Several authors have noted that GER can develop following gastrostomy placement even in children with a negative preoperative evaluation for GER. ${ }^{3,9-11}$ Mollit et a ${ }^{10}$ report a $25 \%$ incidence of symptomatic postgastrostomy GER in 12 patients with negative preoperative evaluations for reflux. Jolley et $\mathrm{al}^{3}$ cite a $66 \%$ incidence of $\mathrm{pH}$ probe-documented GER in nine children receiving gastrostomy alone, with three eventually requiring antireflux procedures. These data have led some authors to suggest that a "protective" antireflux operation should be performed in all patients undergoing gastrostomy placement. ${ }^{3}$

The etiology of reflux following gastrostomy placement is still not completely understood. Possibly, reflux in these children is actually present preoperatively but remains undetected despite sophisticated testing until unmasked by gastrostomy placement. ${ }^{10}$ Therefore, postoperative reflux may actually reflect a limitation of preoperative testing. Other investigators have suggested that Stamm gastrostomy predisposes to the development of GER by altering the angle of Hiss and thereby decreasing the lower esophageal sphincter pressure. ${ }^{1,12}$ 
In this series, 43 children had a negative evaluation for GER using UGI radiography and esophageal $\mathrm{pH}$ probe monitoring. All of these patients underwent Stamm gastrostomy placement, with six (14\%) subsequently developing symptomatic GER; five of these children have undergone Nissen-Hill fundoplication and the sixth has been managed successfully with continuous gastrojejunal feedings. The remaining 37 children have not had any evidence for symptomatic GER at an average follow-up of 21 months (Fig 1). Had a protective antireflux procedure been performed on all children with a negative preoperative evaluation for GER, $86 \%$ of children in this group would have undergone an unnecessary Nissen-Hill fundoplication. The overall mortality for the Nissen fundoplication in neurologically impaired children ranges from $4 \%$ to $24 \%$, with an incidence of postoperative small bowel obstruction ranging from $6 \%$ to $9 \% .^{13-16}$ This study suggests that an antireflux procedure will be unnecessary for $86 \%$ of children with a negative preoperative evaluation for GER. Therefore, given the significant morbidity and mortality associated with fundoplication procedures in this group of patients, we conclude that a protective antireflux operation is not justified.

Although it is possible that further follow-up will identify more children who are currently asymptomatic but who will eventually develop reflux, several authors have noted that GER following gastrostomy occurs early in the postoperative period, with symptoms usually developing from 1 to 18 months following operation. ${ }^{9-11}$ In six of the present patients, symptoms began on average during the $10 \mathrm{th}$ postoperative month. Therefore, late follow-up of the 37 asymptomatic paticnts, although ongoing, is unlikely to demonstrate new cases of gastrostomy-induced GER.
Further, none of the five patients who subsequently required Nissen-Hill fundoplications following gastrostomy suffered any untoward consequences from this two-stage approach. At the onset of vomiting, each child underwent full evaluation for reflux with UGI contrast radiography and $\mathrm{pH}$ monitoring, and, with confirmation of reflux, a Nissen-Hill fundoplication was performed. No increased morbity was documented for this group, and all five children maintained or surpassed their preoperative growth percentile curves with gastrostomy feedings during this interval period. Langer $\mathrm{ct} \mathrm{al}^{11}$ confirm this finding, citing no demonstrable increase in morbidity or mortality in patients who started with gastrostomy alone and subsequently required an antireflux procedure when compared with those patients undergoing an antireflux procedure in conjunction with feeding gastrostomy. Although two of the five patients subsequently required a second Nissen-Hill fundoplication, it is unlikely that this relates to a delay in performing the initial antireflux procedure.

For the majority of brain-damaged children with a negative preoperative evaluation for GER, a protective antireflux operation in conjunction with gastrostomy is unnecessary, and such a procedure adds a sig- nificant increase in surgical morbidity and mortality. Provided that careful follow-up is maintained, children who require a subsequent antireflux procedure following gastrostomy are unlikely to suffer any increased morbidity due to this delay, and may actually benefit from their improved nutritional status prior to undergoing fundoplication. It is concluded that feeding gastrostomy alone should be performed for mentally retarded children without GER who require nutritional support with tube feedings.

\section{REFERENCES}

1. Jolley SG, Tunell WP, Hoelzer DJ, et al: Lower esophageal pressure changes with tube gastrostomy: A causative factor in gastroesophageal reflux in children? J Pediatr Surg 21:624-627, 1986

2. Wesley JR, Coran AG, Sarahan TM, et al: The need for evaluation of gastroesophageal reflux in brain-damaged children referred for feeding gastrostomy. J Pediatr Surg 16:866-871, 1981

3. Jolley SG, Smith EI, Tunell WP: Protective antireflux operation with feeding gastrostomy. Ann Surg 201:736-740, 1985

4. McCauley RGK, Darling DB, Leonidas JC, et al: Gastroesophageal reflux in infants and children: $A$ useful classification and reliable physiologic technique for its demonstration. AJR 130:47-50, 1978

5. Blane CE, Klein MD, Drongowski RA, et al: Gastroesophageal reflux in children: Is there a place for the upper gastrointestinal study? Gastrointest Radiol 11:346-348, 1986

6. Byrne WJ, Euler AR, Ashcraft E, et al: Gastroesophageal reflux in the severely retarded who vomit. Criteria for and the results of surgical intervention in twenty-two patients. Surgery 91:95-98, 1982

7. Raventos JM, Kralemann H, Gray DB: Mortality risks of mentally retarded and mentally ill patients after feeding gastrostomy. Am J Ment Defic 86:439-444, 1982

8. Sondheimer IM, Morris BA: Gastroesophageal reflux among severely retarded children. J Pediatr 94:710-714, 1979

9. Berezin S, Schwarz SM, Halata MS, et al: Gastroesophageal reflux secondary to gastrostomy tube placement. Am J Dis Child 140:699-701, 1986

10. Mollit DL, Golladay ES, Seibert JJ: Symptomatic gastroesophageal reflux following gastrostomy in neurologically impaired patients. Pediatrics 75:1124-1126, 1985

11. Langer JC, Wesson DE, Ein SH, et al: Feeding gastrostomy in neurologically impaired children: Is an antireflux procedure necessary? J Pediatr Gastroenterol Nutr 7:830-836, 1988

12. Canal DF, Vane DW, Goto DW, et al: Changes in lower esophageal sphincter pressure (LES) after Stamm gastrostomy. J Surg Res 42:570-574, 1987 
13. Tunell WP, Smith EI, Carson JA: Gastroesophageal reflux in childhood. Ann Surg 197:560-565, 1983

14. O'Neal JA, Betts J, Ziegler MM, et al: Surgical management of reflux strictures of the esophagus in childhood. Ann Surg 196:453-460, 1982
15. Dedinsky GK, Vane DW, Black CT, et al: Complications and reoperation after Nissen fundoplication in childhoud. Am J Surg 153:177-183, 1987

16. Turnage RH, Oldham KT, Coran AG, et al: Late results of fundoplication for gastroesophageal reflux in infants and children. Surgery 105:457-464, 1989

\section{Discussion}

T. Holder (Kansas City, MO): For the past several years, we have used the same approach but with an attempt to determine the cause of GER in patients with gastrostomies. In our experience, like yours, about $15 \%$ of brain-damaged patients who did not have reflux demonstrable by $\mathrm{pH}$ study have developed it after the gastrostomy. Have you made any conclusions from your data as to whether the reflux was present and not detected by the $\mathrm{pH}$ study or whether it was caused by the gastrostomy?

Our experience with postoperative intestinal obstruction is different from yours. In the first 100 patients undergoing Thal fundoplication, three patients developed intestinal obstruction. At that time, we explored the abdomen thoroughly, occasionally removing the appendix. We subsequently made a concerted effort to stay above the transverse colon. In the last 1,000 patients, only three patients developed intestinal obstruction. Although the lesser procedure (Thal rather than Nissen fundoplication) undoubtedly contributes to the decreased incidence of intestinal obstruction, so does confining the operation to the upper abdomen above the transverse colon.

J. Langer (Hamilton, Ontario): A few years ago at this association meeting, we presented a similar series of patients from Toronto and found a $47 \%$ incidence of symptomatic reflux after gastrostomy alone. The preoperative investigation in those patients consisted only of barium swallow. I think it is very important to point out that in your series the addition of the $\mathrm{pH}$ probe has decreased the incidence to only $15 \%$. Therefore, I would like to underline the importance of the $\mathrm{pH}$ study in evaluating all these patients, unless, of course, the UGI is clearly positive.

E.W. Fonkalsrud (Los Angeles, CA): Most patients who have a feeding gastrostomy inserted eventually end up in a chronic-care institution. Therefore, the volume of feedings placed into the gastrostomy may be unpredictable depending on who provides the care. We have had a few such patients who have received unusually large feedings and have developed reflux with pulmonary aspiration that was not demonstrated by $\mathrm{pH}$ study before the gastrostomy was placed. Following gastrostomy, we have had to go back to perform an antireflux procedure on a few such patients. Therefore, we consider performing an antireflux procedure on brain-damaged patients who may have only mild reflux demonstrated on $\mathrm{pH}$ monitoring.

I was somewhat concerned about the unusually high morbidity and mortality reported. I believe you quoted $4 \%$ to $24 \%$, which seems unusually high. In our experience, and in that of many others, the morbidity and mortality is only minimally different between gastrostomy placement via laparotomy and fundoplication combined with gastrostomy. In patients who have central nervous system disorders, we found that between $25 \%$ and $30 \%$ have delayed gastric emptying and so we routinely study these patients for gastric emptying, as well as for esophageal $\mathrm{pH}$ monitoring. We perform pyloroplasty on approximately $25 \%$ of these patients, which seems to reduce the complications of the fundoplication. Since these patients end up being in institutions for long periods of time, anything we can do to prevent reoperation would seem advisable.

G.M. Haase (Denver, CO): I would like to ask the author to comment on the etiology of the neurological damage in their patients. With our multiple-channel studies, we noticed a difference in pattern between the children who had global neurological injury and those who had an acute cerebral event, perhaps after trauma. We agree that about $70 \%$ of these children did have reflux at the time they were evaluated for a feeding gastrostomy, but we were pretty much able to detect a difference between the two basic patient groups. Did you look at your data in that way, perhaps to be able to predict essentially which of the neurologically damaged children would almost always need an antireflux procedure at time of gastrostomy tube placement and which might need it infrequently?

A. Peña (New York, NY): I wonder if the technique used for the opening of the gastrostomy has something to do with the reflux that we may see after the gastrostomy is opened. We followed the suggestion of Dr Stringel recently in a patient who was mentally retarded, required a gastrostomy, and who had documented reflux before the operation. My associate Dr 
Shrock opened a gastrostomy but placed the gastrostomy closer to the lesser curvature of the stomach and intentionally pulled the stomach down as to create a gastropexy that will make the Hiss angle more acute, whereas if you put it closer to the greater curvature you may decrease that angle and may provoke reflux. I wonder if you could comment on that?

M. Schwartz (Sacramento, CA): The question I would like to posc rcgards the rclationship of the age of the patients and the incidence of GER. I wonder if the patients who did not have reflux when studied were younger than those that were identified as having reflux and whether 21 months of follow-up is adequate to determine whether they will or will not develop reflux? It has been my impression that neurologically impaired children less than 3 years old have less problems than older children from GER.

M.J. Wheatley (response): Dr Holder, it's not clear exactly why $15 \%$ of the children develop GER following fundoplication. This may be secondary to gastrostomy tube placement with alteration of the angle of Hiss or may simply reflect a variable lack of sensitivity of pre-operative $\mathrm{pH}$ monitoring. We agree that the bowel should be handled gently during operation, and that confining the operation as much as possible to the region above the colon may help prevent adhesions and thereby reduce the incidence of postoperative bowel obstruction. I would like to reemphasize what $\mathrm{Dr}$ Langer said, that $\mathrm{pH}$ probe monitoring increases the sensitivity and specificity of the diagnosis of preoperative GER and will greatly decrease the number of children who receive gastrostomy alone who will eventually need an antireffux procedure. Dr Fonkalsrud, it is difficult to determine what type of feedings children will receive after they have feeding gastrostomy placed; therefore, we have not done antireflux procedures in anticipation of children receiving bolus feedings following gastrostomy placement. Mortality, in this series, after Nissen fundoplication was only $1 \%$, although in the literature figures between $4 \%$ and $24 \%$ have been quoted. So clearly the neurologically impaired child is at increased risk with an antireflux procedure. Gastric emptying can be a problem. In our total series of Nissen fundoplications we found that delayed gastric emptying occurred with some patients with breakdown of the Nissen fundoplication; therefore, we have undertaken a study evaluating children preoperatively for gastric emptying to determine how this impacts on success or failure of antireflux surgery. Dr Haase, we have not found any difference in the $\mathrm{pH}$ scores related to different etiologies of neurological dysfunction. Dr Peña, when we place the gastrostomy we attempt to avoid any alteration in the angle of Hiss by placing the G-tube along the greater curve and fixing the stomach without tension to the anterior abdominal wall. And Dr Schwartz, with respect to the adequacy of our follow-up, most series relevant to this topic have found that GER reflux following gastrostomy placement occurs relatively early. In this series, the average for 6 patients was 10 months, with a range from 4 to 20 months. We believe that GER following gastrostomy placement occurs relatively early in the postoperative period, and so that at 21 months of follow-up, most of the children who will develop GER will have already done so. However, we are continuing our careful follow-up. 